\title{
Adolescents and Children in Global Media Landscape: From Risks to Rights
}

\author{
Elisabeth Staksrud \\ Department of media and communication, University of Oslo, Norway \\ Tijana Milosevic \\ Department of media and communication, University of Oslo, Norway
}

\begin{abstract}
We examine what we see as some of the key developments in the field of adolescents and children and media research. With the caveat as regards to our specific research perspective and possible bias stemming from there, we identify two important developments that have begun to take place in the past five years- 1 . The enrichment of the field by data and perspectives coming from so-called developing countries. 2. A greater tendency towards citing research evidence in response to public anxieties over youth engagement with (especially) digital media. A shift towards rights-based framework and focus on media opportunities is discussed as well.
\end{abstract}

Keywords: children, adolescents, media, children's rights, digital media, risks, opportunities

\section{Introduction}

The research field on adolescents, children and media is multi-faceted, employing a variety of methods, and goes well beyond the disciplinary boundaries of media and communication to span education, developmental and clinical psychology, humancomputer interaction, Internet studies, pediatric medicine, neuroscience and law, among other fields (see e.g. Institute of Digital Media and Child Development, 2016; Lemish, 2015). We thus need to signal that, as authors, we provide this critical 
overview from our perspective, which is that of the EU Kids Online members —an interdisciplinary research network of about 150 scholars in 33 European countries who have been researching children and adolescents in the context of media, and more specifically digital environments, since 2006. Given the vast scope of the field, and the limits of this article, we cannot capture the full variety of topics, perspectives on issues and relevant developments across these in the past five years -that would likely require a book volume. Rather, with our particular perspective, we will provide a cross-sectional overview of research trends, theoretical, and policy implications with respect to education, and relevant stakeholders such as parents and regulators and children themselves.

We have identified two important shifts that have begun to take place in the past five years. First, the geographical and cultural hegemony of theoretical models from European and global north perspectives is now being increasingly enriched with contributions on children's media use from developing countries (or the so-called “Global South”), with a significant contribution from Global Kids Online project ${ }^{1}$ (Barbosa et al., 2013; Ravalli \& Paoloni, 2016; Tan, Estacio, Ylade, 2016; Popadic et al., 2016). Having in mind that a survey that would match the scale and variety of topics captured in the EU Kids Online 2010/2011 survey - involving a representative sample of 25,000 children and teens, age 9-16, and their parents, in 25 European countries, which was also replicated in Australia (EU Kids Online, 2014; Green et al., 2013) - has not been conducted in the United States, for instance ${ }^{2}$, signifies that we

\footnotetext{
${ }^{1}$ Established with United Nations International Children's Emergency Fund (UNICEF) and the London School of Economics: http://www.1se.ac.uk/media@1se/research/Global-Kids-Online.aspx

${ }^{2}$ We do acknowledge the existence of large scale efforts (e.g. Lenhart, 2015), some of which involve adolescents above the age of 15 (e.g. Lenhart et al., 2016), we are merely saying that large and
} 
are still very much in need of robust studies from the developed countries (e.g. Mitchell et al., 2012) and especially longitudinal ones. Nonetheless, cultural diversification generated from findings in geographic areas where social context of media use can be significantly different from dominant trends in the West, is very much welcomed.

Viewing children's lives through "a broad structuration approach," Global Kids Online project recognizes "the contingent interplay between societal structures of economy, politics and culture, and the meanings and actions of individuals and communities as they engage with and thus shape the structures that, in turn, shape the conditions within which they live" (Stoilova et al., 2016, p. 457). The key challenge then is to examine to what extent the use of digital technologies in global contexts mediates children's well-being and their rights, in a positive or negative manner (Stoilova et al., 2016, p. 457).

While it may be tempting to extrapolate the findings about the impacts of children's digital media use from the developed world onto the developing countries, there are some social, economic and media-use related factors that may create distinct environment and outcomes. These can include quality and place of internet access, large country populations, or lack of policies oriented at child well being at the national level (Livingstone, 2014; Byrne et al, 2016). The very meaning of internet use changes in the global context (Livingstone \& Bulger, 2014), as it becomes increasingly mobile in lower income countries (Byrne et al., 2016). Less frequent internet use and greater obstacles to access can result in less competence in terms of digital skills and e-safety. Consider the findings from South Africa which revealed 
that when children relied primarily on mobile devices as their point of access they were also less likely to develop skills they could not practice on such devices, e.g. coding or website design (Byrne et al., 2016; Phyfer, Burton \& Leoschut, 2016). In Chile, a third of children never use the internet at school (Cabello \& Claro, 2017). Researchers found it difficult to draw generalizations as regards to risks and opportunities of children's use of digital technology across the developing countries (Byrne et al., 2016). While in some surveyed developing countries around a third of children experienced something upsetting online in the past year, and most children considered the internet beneficial (e.g. Philippines, Serbia and South Africa), in other places (e.g. Argentina) most children reported problematic experiences (Byrne et al., 2017). ${ }^{3}$ This may indeed signal more problems online for children in Argentina, but it could also be that Argentinian children are more familiar with the internet and therefore more likely to think of risks and perceive them or that they engage in more exploration online which can expose them to more risks (Byrne et al., 2016; Ravalli \& Paoloni, 2016). In some countries children were going online at younger ages but we do not have sufficient indication as to why this might be the case (e.g. infrastructure around early childhood care, parental attitudes etc.) Researchers agree that more study is needed, as we do not know yet under which circumstances and for which children in these countries the use is more likely to result in harm rather then benefits. The task of systematic comparison of these most recent findings to the findings from the developed countries is yet to be undertaken.

\footnotetext{
${ }^{3}$ According to the EU Kids Online survey from 2010, with 25,000 internet using children in Europe, age $9-16,12 \%$ of these children reported that something upset or bothered them online in the past year. A smaller sample in 2014 revealed that this was the case with $17 \%$ of children. (EU Kids Online, 2014).
} 
The second development we have outlined concerns the wider societal relevance of children and media research. After more than a decade of focus on evidence-based policy, we are now witnessing a climate where such evidence is beginning to be used as a response to public anxieties over risk of harm as regards to young people's interaction with digital technology. ${ }^{4}$ Specifically, earlier risk of harmdriven discourse around young people and media, and digital media in particular (see e.g. Buckingham, 2011; Livingstone, 2009; Marwick, 2008), has begun to incorporate a greater research interest in opportunities (for learning, development, leisure, etc.) that digital spaces can afford. To an extent at least, this development appears to be reflected in the revised recommendations of the American Academy of Pediatrics as regards to screen time for children. While the report still pays due diligence to the number of hours spent with screens per day and does so in reference to specific age groups, there is a growing recognition of the context of use - what activity the child is engaged with using various media technologies and how the time spent with technologies - affects or relates to other activities important for child development (American Academy of Pediatrics, 2016; Livingstone, 2016b).

These developments converge in an increasing understanding that research on youth and media is beginning to be less about what media does to children and adolescents, and rather more about how media and digital spaces in particular are

\footnotetext{
${ }^{4}$ Some may observe that this observation has some notable exceptions-perhaps most recently in the context of European General Data Protection Regulation (GDPR), whose passage was widely critiqued for not being research-driven and failing to consult children on a matter that concerned them (See, e.g. boyd, 2015; Carr, 2016; Livingstone, 2016c.). Nonetheless, the very fact that the lack of debate was criticized on these accounts can also be seen as a positive change that empirical evidence brought to the debate.
} 
actively appropriated by youth (boyd, 2014); and how they contribute to youth lives in the context of family, school, community, and wider social and cultural-level factors, thus interacting with various variables on all these levels. This point is illustrated in Figure 1, which allows us to ask a simple, yet core question: what difference does the digital - or rather in wider context — the media - make?

(Livingstone, Mascheroni, \& Staksrud, 2017). While this model is developed to theorize over children's online engagements, it can also serve as a wider example of children, adolescents and media research in general.

Figure 1: The EU Kids Online revised model of children's outcomes of internet use

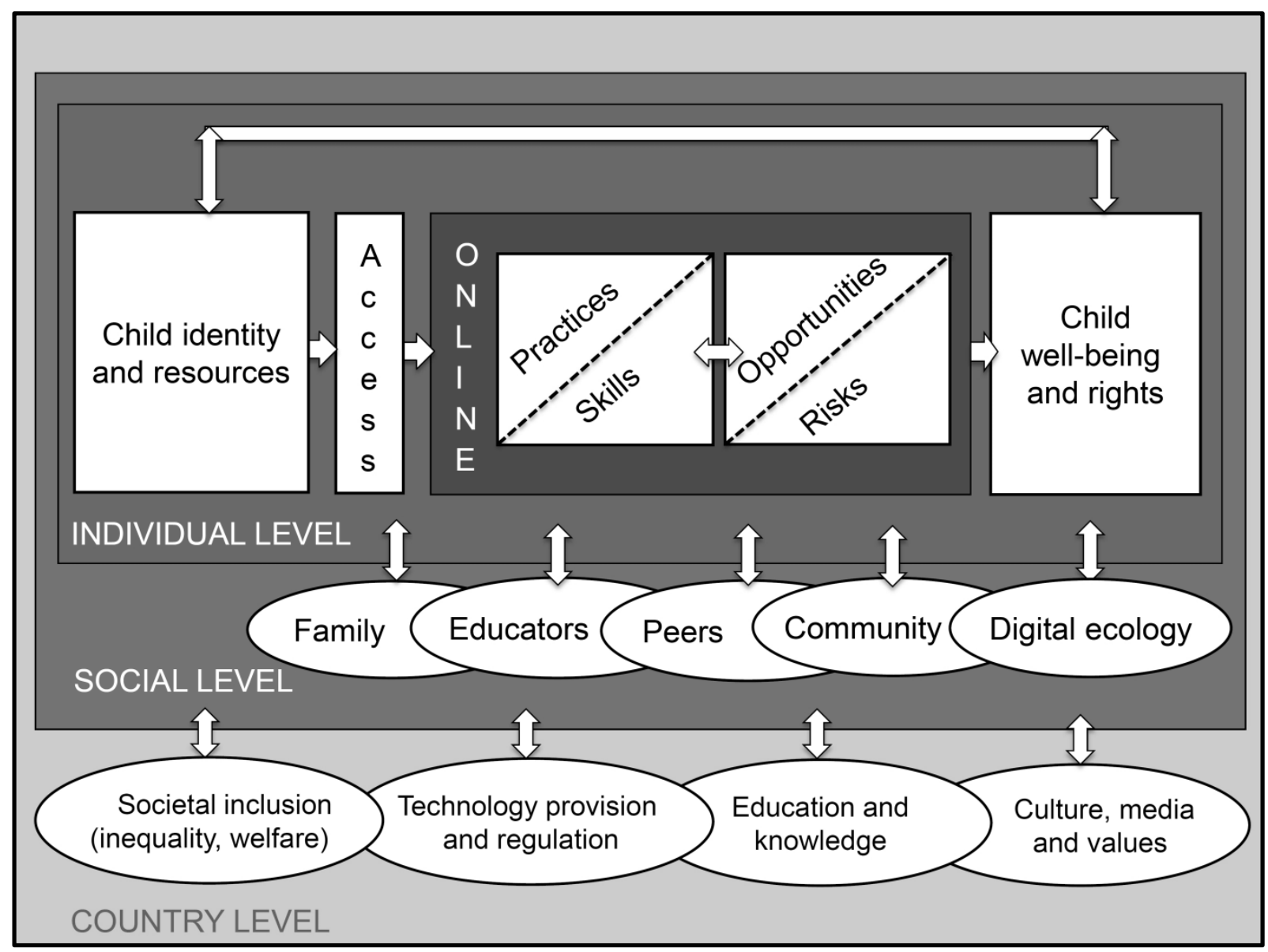

(as published in Livingstone et al., 2017 and originally cited in an EU Kids Online report freely available online: Livingstone, Mascheroni \& Staksrud, 2015).

The model, developed from over a decade of empirical findings and analysis, suggests how the question of how the use of media can contribute, or not, to children's well- 
being and rights cannot be answered only by looking at the individual child and his or her access, media practises, psychological resources and skills. Rather, the issue requires insights also from how the social level, such as family, friends, school and on- and offline communities, contributes, or not, to how a child relates to media access, input and output. The model also includes how one must consider factors on the national, or even supranational level. For instance, the level of equality and societal inclusion in a country, or the degree to which technological tools and skills are made available to the public in general and through the school system in particular, will influence the access, skills and coping mechanisms of the individual child faced with media and with communication technology. How the public discourse plays out, the level of regulation, anxiety and/or literacy might influence how parents and teachers talk to children (or not) about media and communication technologies, which again influences the individual child's access, skills and coping strategies when faced with mediated risks and opportunities. Likewise, the experiences in families, schools and communities as children access and use the media, might influence and even put pressure on national level processes, such as regulation, law-making, and national curriculums. Thus, the model illustrates the complex and multileveled field that is now children and media research.

This shift in perspective from the sole focus on risks of harm to opportunities is also mirrored in an increasing discussion about children's rights - an understanding that children's and adolescents' presence in increasingly digital environments is a fundamental human right. That is, it is increasingly argued that in their interaction with media, children not only have the right to protection - but also to provision and participation. More precisely, they have the right to be protected from harm stemming from possible negative media experiences, but also the right to participate 
as active agents in spaces that are of crucial importance for their cognitive and emotional development, while being provided with media content and technological affordances that foster this development (Livingstone \& Bulger, 2014; Livingstone, Carr \& Byrne, 2015; Staksrud, 2013). In accordance with this understanding, leading children and media scholars invite colleagues to attempt to re-consider the traditional understanding of the field from the perspective of "media effects" and examine the value-added of the "children's rights" approach (Livingstone, 2016a). Looking at children's human and political rights can facilitate such explanations, not only to highlight the entry points between the different levels of regulation, but also to analyze the possible consequences that the regulation and its embedded preconceptions and assumptions have for these rights. At the same time, the very conceptualization of children's rights as envisaged in the United Nations Convention on the Rights of the Child and its basis in neoliberal values is subject to critique and the application of such model onto developing countries is likely to require critical reconsideration (Blackburn, 2011; Asthana, 2017).

\section{Challenges for the future}

These large patterns and developments point towards specific challenges and directions for future research. Firstly, while the AAP may provide recommendations on screen time, as Prof. Sonia Livingstone observes: "there isn't yet a robust body of research on the effects of digital media on children, yet parents want guidance now" (Livingstone, 2016b, para 1). Likewise, the methodological difficulties remain, such as the inability to control all the relevant factors necessary to discern specific media effects, i.e., to what extent is a learning or a harmful outcome a result of media interaction as opposed to family, school, social or other influences? In addition, and 
despite some important strides in researching very young children, especially under the age of eight (e.g. Chaudron, 2015), efforts in this direction remain in great need of further development.

Secondly, media has long stopped being a factor that is merely a natural socializing agent: with the so-called internet of things (IoT) or internet-connected toys (smart toys), wearable technologies, smart household appliances and virtual realitymedia is seamlessly and literally integrated into their lives. While young people's interaction with such technologies, along with privacy issues in this context, are an increasingly studied topic (e.g. Gasser \& Cortesi, 2012; Holloway \& Green, 2016; Madden et al., 2013; Montgomery, Chester, Milosevic, 2017) — such media use presents a challenge for future research from an ethical standpoint. Moreover, the promise of big data as enabling new opportunities for research also evokes ethical questions regarding the use of such data for research purposes. For instance, is it ethically permissible to use publicly shared data without young users' consent (even when properly anonymized)? The same ethical concerns arise in conjunction with analyses of behavioral data collected through wearable devices or by smart toys while young users may not even realize they are being recorded, i.e., the data children and adolescents may not be aware of leaving behind. Furthermore, this increasing versatility of digital ecologies brings particular challenges for media literacy and digital citizenship scholars. In a world where "fake news" - especially, but not solely through fraudulent websites and its spread via social media - has become an increasing problem, teaching the ability to separate fact from fiction and to critically question sources, motives and meanings, is of central importance for the field. 


\section{The future of children and media research as a field}

The field of children and media (CAM) or children, youth and media (CYM) is growing and has acquired a critical momentum, as witnessed in an increasing number of widely cited publications in the Journal of Children and Media (JOCAM), edited by recognized communication scholars, Dr. Amy Jordan and Dr. Dafna Lemish, and with many leading scholars on its Board. The Journal has most recently celebrated its $10^{\text {th }}$ year anniversary with a special issue on trends in the field. In addition, just this year, an interdisciplinary edition devoted to the issue of children's digital rights has appeared in the flagship journal, New Media \& Society (2017), also signaling the pressing importance of these topics. A future research challenge for the CAM field is to engage with media and communication scholars studying other topics, in order to show the extended theoretical and societal relevance of our work (Staksrud, 2016). For example, it is not always evident that our work has implications for the research designs of those who study communication among adults. But keeping in mind that young people tend to be early adopters of technologies and social trends, and as previously argued,

if there is a new research challenge, a problem, an ethical or a methodological dilemma, a regulatory innovation; chances are pretty good that scholars in the field of children and media have already started working on it and can offer insights and a suggested path for a way forward. (Staksrud, 2016, p. 136)

Furthermore, having in mind our heightened ethical standard of care, which stems from the need to protect a vulnerable population, we can also provide useful guidance on how to ethically handle the excitement over increasing access to big data. Finally, given that the discourse over child protection from media-related harms has historically been used as an excuse for curbing central democratic tenets such as 
freedom of speech — the findings from our analyses speak to issues that go beyond youth and have relevance for the state of democracy in our societies (Buckingham, 2011; Livingstone, 2009; Staksrud, 2013, 2016).

\section{References:}

American Academy of Pediatrics. (2016, October 21). American Academy of Pediatrics Announces New Recommendations for Children's Media Use. Retrieved from:_https://www.aap.org/en-us/about-the-aap/aap-pressroom/pages/american-academy-of-pediatrics-announces-newrecommendations-for-childrens-media-use.aspx

Asthana, S. (2017). Translation and localization of children's rights in youthproduced digital media in the Global South: A hermeneutic exploration. New Media \& Society, 19(5), 686-700.

Barbosa, A., O’Neill, B. Ponte, C., Simoes, J.A., Jereissati, T. (2013). Risks and Safety on the internet. Comparing European and Brazilian results. Retrieved from: http://www.lse.ac.uk/media@,1se/research/ResearchProjects/Researching-Childrens-Rights/pdf/Barbosa-et-al-(2013).-Risks-andsafety-on-the-internet.-Comparing-Brazilian-and-European-children.pdf

boyd, d. (2014). It's complicated: the social lives of networked teens. Yale University Press: New Haven + London

boyd, d. (2015, December 18). What if social media becomes 16-plus? New battles concerning age of consent emerge in Europe. The Medium. Retrieved from: https://medium.com/bright/what-if-social-media-becomes-16-plus866557878f7\#.skvnifxhd

Buckingham, D. (2011). The Material Child. Cambridge, UK: Polity.

Blackburn, R. (2011). Reclaiming Human Rights. The Left Review, 69, 126-138.

Byrne, J., Kardefelt-Winther, D., Livingstone, S., Stoilova, M. (2016). Global Kids Online Research Synthesis 2015-2016. UNICEF. Office of Research Innocenti and London School of Economics and Political Science.

Cabello, P., \& Claro, M. (2017). General Results, Kids Online Survey Chile. Santiago: Kids Online Chile. 
Carr, J. (2016, March 31). John Carr on the GDPR: Poor process, bad outcomes. Retrieved from: https://www.betterinternetforkids.eu/web/portal/news/detail?articleId=687465

Chaudron, S., (2015). Young children (0-8) and digital technology: A qualitative, exploratory study across seven countries. European Commission Joint Research Centre. Retrieved from: http://www.1se.ac.uk/media@,1se/research/ToddlersAndTablets/RelevantPublic ations/Young-Children-(0-8)-and-Digital-Technology.pdf

EU Kids Online. (2014). EU Kids Online: Findings, methods, recommendations. EU Kids Online, LSE. Retrieved from: http://eprints.lse.ac.uk/60512/

Gasser, U. \& Cortesi, S. (2012). Parents, Teens and Online Privacy. Berkman Klein Center for Internet \& Society at Harvard University. Retireved from: https://cyber.harvard.edu/publications/2012/parents teens privacy

Green, L., Brady, D., Holloway, D., Staksrud, E., Olafsson, K. (2013). What bothers Australian children online? Children comment on bullies, porn, and violence. Retrieved from: http://www.cci.edu.au/reports/WhatBothersAusKidsFIN.pdf Holloway, D., \& Green, L. (2016). The Internet of Toys. Communication Research and Practice, 2(4), 506-519. https://doi.org/10.1080/22041451.2016.1266124 Institute of Digital Media and Child Development (2016). 2015 Digital Media and Developing Minds Conference. Retrieved from: http://www.childrenandscreens.com/conference/

Lenhart, A. (2015, April 6). Teens, social media \& technology overview 2015. Pew Research Center. Retrieved from: http://www.pewinternet.org/2015/04/09/teens-social-media-technology-2015/

Lenhart, A., Ybarra, M., Zickuhr, K., Price-Feeney, M. (2016, November 21). Online harassment, digital abuse and cyberstalking in America. Data \& Society Research Institute, Center for Innovative Public Health Research. Retrieved from: https://datasociety.net/pubs/oh/Online_Harassment_2016.pdf

Lemish, D. (2015). Introduction: children, adolescents and media: creating a shared scholarly arena. In: D. Lemish (Ed.), The Routledge Inernational Handbook of Children, Adolescents and Media (pp. 1-10). London \& New York: Routledge.

Livingstone, S. (2009). Children and the Internet. Cambridge: Polity Press. 
Livingstone, S. (2014, September 12). Digital Media and Children's Rights. Media

Policy Project. Retrieved from:

http://blogs.lse.ac.uk/mediapolicyproject/2014/09/12/sonia-livingstone-digitalmedia-and-childrens-rights/

Livingstone, S. (2016a). Reframing media effects in terms of children's rights in the digital age. Journal of Children and Media, 10(1), 4-12.

doi:10.1080/17482798.2015.1123164

Livingstone, S. (2016b). New 'screen time' rules from the American Academy of

Pediatrics. Parenting for a Digital Future. Retrieved from:

http://blogs.1se.ac.uk/parenting4digitalfuture/2016/10/21/new-screen-timerules-from-the-american-academy-of-pediatrics/

Livingstone, S. (2016c). To be 13 or 16 that is the question: The implications for UK teenagers of the European General Data Protection Regulation. Parenting for a Digital Future. Retrieved from:

http://blogs.lse.ac.uk/parenting4digitalfuture/2016/11/23/to-be-13-or-16-thatis-the-question/

Livingstone, S., \& Bulger, M. (2014): A Global Research Agenda for Children's Rights in The Digital Age, Journal of Children and Media, DOI:

10.1080/17482798.2014.961496

Livingstone S., Carr, J. \& Byrne, J. (2015) One in Three: Internet Governance and Children's Rights. Global Commission on Internet Governance Paper Series 22. Retrieved from: www.cigionline.org/publications/one-three-internetgovernance-and-childrens-rights

Livingstone, S., Mascheroni, G., Staksrud, E. (2015). Developing a framework for researching children's online risks and opportunities in Europe. EU Kids Online report. Retrieved from:

http://eprints.1se.ac.uk/64470/1/ 1se.ac.uk storage_LIBRARY Secondary li bfile_shared_repository_Content_EU\%20Kids\%20Online_EU\%20Kids\%20O nline Developing\%20framework\%20for\%20researching 2015.pdf

Livingstone, S., Mascheroni, G., \& Staksrud, E. (2017). European research on children's internet use: Assessing the past, anticipating the future. New Media \& Society, 1-19. doi:10.1177/1461444816685930 
Madden, M., Lenhart, A., Cortesi, S., Gasser, U., Duggan, M., Smith, A., \& Beaton, M. (2013). Teens, Social Media \& Privacy. Pew Research Center. Retrieved from: http://www.pewinternet.org/2013/05/21/teens-social-media-and-privacy/

Marwick, A. E. (2008). To catch a predator? The MySpace moral panic. First Monday, 13(6). Retrieved from http://journals.uic.edu/ojs/index.php/fm/article/view/2152/1966

Mitchell, K.J., Finkelhor, D., Jones, L.M., Wolak, J. (2012). Prevalence and characteristics of youth sexting: A national study. Pediatrics 129(1), 13-20.

Montgomery, K., Chester, J., \& Milosevic, T. (2017). Ensuring young people's digital privacy as a fundamental right. In B. De Abreu, A. Lee, J. McDougall, J. Melki, \& P. Mihailidis (Eds.), International Handbook of Media Literacy. New York, NY: Routledge

Phyfer, J., Burton, P., \& Leoschut, L. (2016).Global Kids Online South Africa: Barriers, opportunities and risks. A glimpse into South African children's internet use and online activities. Technical report. Cape Town: Center for Justice and Crime Prevention. Retrieved from: http://blogs.lse.ac.uk/gko/research-results-southafrica/

Popadić, D., Pavlović, Z., Petrović, D. and Kuzmanović, D. (2016) Global kids online Serbia: Balancing between Opportunities and Risks. Results from the Pilot Study, Belgrade: University of Belgrade, at: www.globalkidsonline/serbia Ravalli, M and Paoloni, P (2016) Global Kids Online Argentina: Research study on the perceptions and habits of children and adolescents on the use of technologies, the internet and social media. Buenos Aires: UNICEF Argentina, www.globalkidsonline/argentina

Staksrud, E. (2013). Children in the Online World: Risk, Regulation, Rights. London: Ashgate.

Staksrud, E. (2016). Researching children and media: Our Herculean task. Journal of Children and Media. doi: 10.1080/17482798.2015.1121890

Stoilova, M., Livingstone, S., Kardefelt-Winther, D. (2016). Global Kids Online: Researching children's rights globally in the digital age. Global Studies of Childhood,6(4), 455-466.

Tan, M., Estacio, L., and Ylade, M. (2016). Global Kids Online in the Philippines. Country Report. Manila: University of the Philippines Manila. Available from: www.globalkidsonline/philippines 
